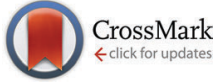

Cite this: New J. Chem., 2016, 40, 994

Received (in Montpellier, France) 1st May 2015,

Accepted 16th November 2015

DOI: $10.1039 / c 5 n j 01099 c$

www.rsc.org/njc

\title{
Enhancement of photochemical heterogeneous water oxidation by a manganese based soft oxometalate immobilized on a graphene oxide matrix
}

\author{
Santu Das, Archismita Misra and Soumyajit Roy*
}

\begin{abstract}
Development of efficient and oxidatively stable molecular catalysts having abundant transition metals at the active site is an immediate challenge to synthetic chemists in order to photochemically split water into clean fuels oxygen and hydrogen to serve the ever-increasing energy demand. Herein we report a soft-oxometalate (SOM)-based heterogeneous photocatalytic system which effectively performs water oxidation giving oxygen. In the present work we placed a double sandwich type manganese-based polyoxometalate (POM), Na $\mathrm{Na}_{17}\left[\mathrm{Mn}_{6} \mathrm{P}_{3} \mathrm{~W}_{24} \mathrm{O}_{94}\left(\mathrm{H}_{2} \mathrm{O}\right)_{2}\right] \cdot 43 \mathrm{H}_{2} \mathrm{O}$, on an electroactive graphene oxide matrix and synthesized a new SOM $\left[\mathrm{Na}_{17}\left[\mathrm{Mn}_{6} \mathrm{P}_{3} \mathrm{~W}_{24} \mathrm{O}_{94}\left(\mathrm{H}_{2} \mathrm{O}\right)_{2}\right] \cdot 43 \mathrm{H}_{2} \mathrm{O}\right.$ @graphene oxide] 1 and performed water oxidation with it. The efficiency of photocatalytic water oxidation by SOM 1 is almost double than in the case of $\mathrm{Na}_{17}\left[\mathrm{Mn}_{6} \mathrm{P}_{3} \mathrm{~W}_{24} \mathrm{O}_{94}\left(\mathrm{H}_{2} \mathrm{O}\right)_{2}\right] \cdot 43 \mathrm{H}_{2} \mathrm{O}$ alone. The rationale behind this lies in the electron accepting nature of the graphene sheets which effectively relay the electrons generated in the water oxidation reaction, thus facilitating the forward reaction and increasing the oxygen yield. Variation of catalyst loading, $\mathrm{pH}$-dependent and time-dependent experiments are performed to study their effects on photocatalytic water-splitting. The reaction kinetics is sigmoidal in nature, suggesting the heterogeneous nature of catalysis. The composite catalyst system is observed to be stable towards the reaction conditions.
\end{abstract}

\section{Introduction}

Water oxidation is one of the most promising routes towards the global goal of alternative energy. ${ }^{1-4}$ Many research groups have developed robust catalysts for efficient water oxidation. ${ }^{5-7}$ Recently chemists have been interested in developing molecular water oxidation catalysts by using cheap and abundant transition metals. ${ }^{6,8}$ Different chemical species are used as catalysts for that purpose, e.g. metal organic complexes, ${ }^{9-24}$ nanomaterials, ${ }^{25-29}$ and the recently developed polyoxometalates. ${ }^{6,8,30-42}$ Polyoxometalates (POM) show higher stability in an oxidizing environment compared to metal-organic complexes where organic ligands tend to get easily oxidized and thus offer better catalyst stability. Different routes of water splitting have been explored, such as chemical, ${ }^{9,10}$ electrochemical ${ }^{2,43-45}$ and photoelectrochemical methods. ${ }^{46-52}$ However, photochemical water oxidation seems to be the most facile and clean technique. ${ }^{6,13,53,54}$

A recent challenge in photochemical water oxidation by polyoxometalates is to enhance the oxygen generation and increase the turnover number (TON) of the reaction. ${ }^{16} \mathrm{Up}$ to now an

EFAML, Material Science Centre, Department of Chemical Science, Indian Institute of Science Education and Research Kolkata, Mohanpur-741246, India.

E-mail: s.roy@iiserkol.ac.in iridium based complex has shown the maximum TON reported by Crabtree and Brudvig. ${ }^{55}$ We are interested in observing whether the reaction efficiency can be enhanced without changing the active center of the catalyst. It is known that POMs can easily be immobilized on the electroactive surface to form stable composite systems. ${ }^{56}$ So, we ask whether it is possible to employ a related composite system to perform water oxidation experiments. ${ }^{29,33,57}$

Recently, the Hill group developed a similar method using graphene modified electrodes and ruthenium based POM as active catalyst. ${ }^{57}$

The graphene modified electrodes show excellent catalytic activity and high stability toward the electrochemical water oxidation reaction at neutral $\mathrm{pH}$. This work showed enhanced water oxidation reaction electrochemically. ${ }^{57}$ Here we ask whether it is possible to make a soft oxometalate ${ }^{56,58-61}$ based on polyoxometalate-graphene oxide to enhance the efficiency of photochemical water oxidation.

In our present work we use a manganese based polyoxometalate $\mathrm{Na}_{17}\left[\mathrm{Mn}_{6} \mathrm{P}_{3} \mathrm{~W}_{24} \mathrm{O}_{94}\left(\mathrm{H}_{2} \mathrm{O}\right)_{2}\right] \cdot 43 \mathrm{H}_{2} \mathrm{O}$ and synthesize a SOM 1 by immobilizing it on a graphene oxide surface $\left[\mathrm{Na}_{17}\left[\mathrm{Mn}_{6} \mathrm{P}_{3} \mathrm{~W}_{24} \mathrm{O}_{94}\left(\mathrm{H}_{2} \mathrm{O}\right)_{2}\right] \cdot 43 \mathrm{H}_{2} \mathrm{O}\right.$ @graphene oxide $]$ 1. This catalyst shows a turnover number of 22 at $\mathrm{pH} 8$ for WO reaction. The SOM 1 dispersion is prepared by sonication. 


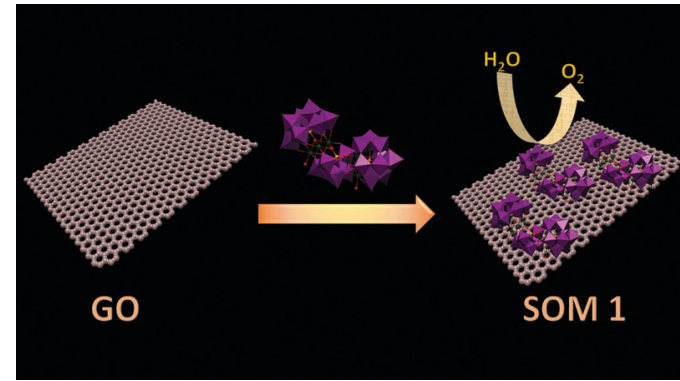

Fig. 1 Schematic diagram of the overall process.

Formation of the composite is confirmed by Raman spectra, SEM images and EDX data. Finally we use this SOM as a photocatalyst in water oxidation (Fig. 1). Interestingly, we observe that in the presence of the graphene oxide matrix the water oxidation activity of Mn-POM is almost doubled. A detailed account of synthesis and characterization of the composite catalyst and observations related to photochemical water oxidation studies are provided in the following sections.

\section{Result and discussion}

Formation of the SOM 1 composite based on graphene oxide

SOM 1 is prepared by following the classical route of immobilization of POM on an electroactive surface. ${ }^{56}$ In our present study we initially prepared graphene oxide dispersion in water. To this dispersion $\mathrm{Na}_{17}\left[\mathrm{Mn}_{6} \mathrm{P}_{3} \mathrm{~W}_{24} \mathrm{O}_{94}\left(\mathrm{H}_{2} \mathrm{O}\right)_{2}\right] \cdot 43 \mathrm{H}_{2} \mathrm{O}$ (Fig. 2) was added and the mixture was sonicated to finally get the composite SOM 1, which forms a stable dispersion. Composite formation

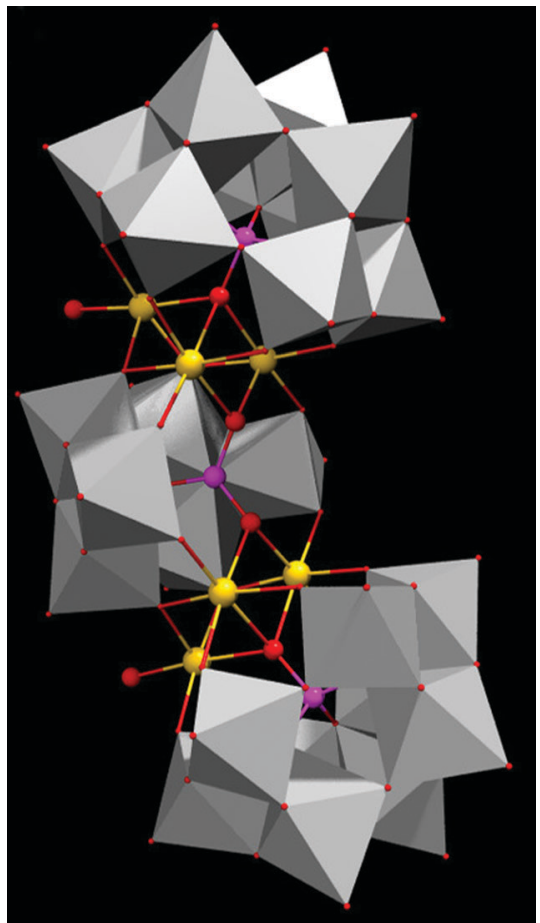

Fig. 2 Single crystal structure of the POM constituent of SOM 1.

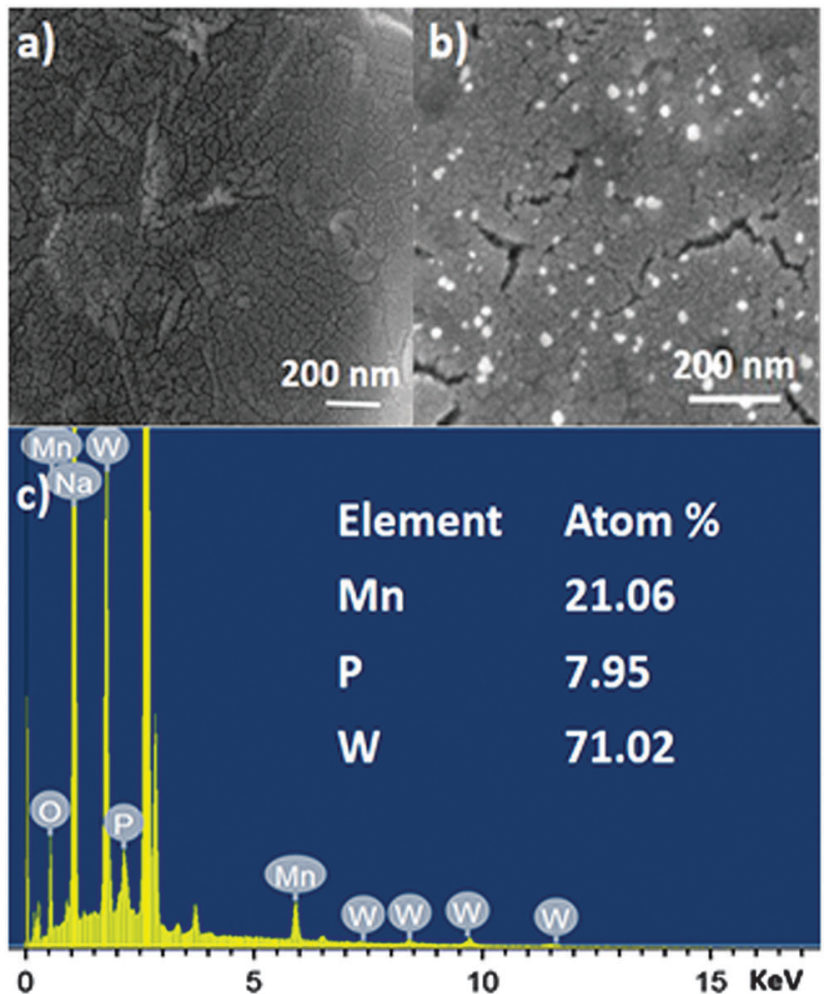

Fig. 3 SEM images of (a) graphene oxide surface. (b) SOM 1, defined by aggregate nanospherical POMs immobilized on the graphene oxide layers. (c) EDX spectrum of SOM 1

was characterized by using Raman spectroscopy, SEM and EDX analysis.

\section{Scanning electron microscopy (SEM): morphology of SOM 1}

GO shows nanosheet type morphology. It is observed from scanning electron microscopy (Fig. 3a). The SOM 1 shows nanospheres embedded on graphene oxide layers (Fig. 3b). The white bright spot indicates the clustering of POM, suggesting that POM units are attached to the surface of GO by electrostatic interactions, as GO has an electron deficient surface (positively charged) and POM are large polyanions (negatively charged). This further indicates the formation of the composite in the reaction system. From the EDX data we can also infer that the molecular integrity of POM is intact in SOM 1. [Note: manganese, phosphorus and tungsten are present in the expected correct ratio of POM in SOM 1 (Fig. 3c).]

\section{HATR-IR spectroscopy and stability of POM in SOM 1}

HATR-IR spectroscopy of SOM 1 and also HATR-IR spectroscopy of the POM constituent were performed. It was observed that a few broad bands were obtained in each case in the IR spectrum. This broadness is possibly due to the low concentration of the sample in the dispersion. Here we observed common peaks for POM and SOM 1 at 1637, 693, 569, $496 \mathrm{~cm}^{-1}$ respectively (Fig. 4a). Thus from the IR-spectrum we can conclude that the POM constituent remains stable and intact in the SOM 1 after composite formation and no catalyst is degraded at all. We further 

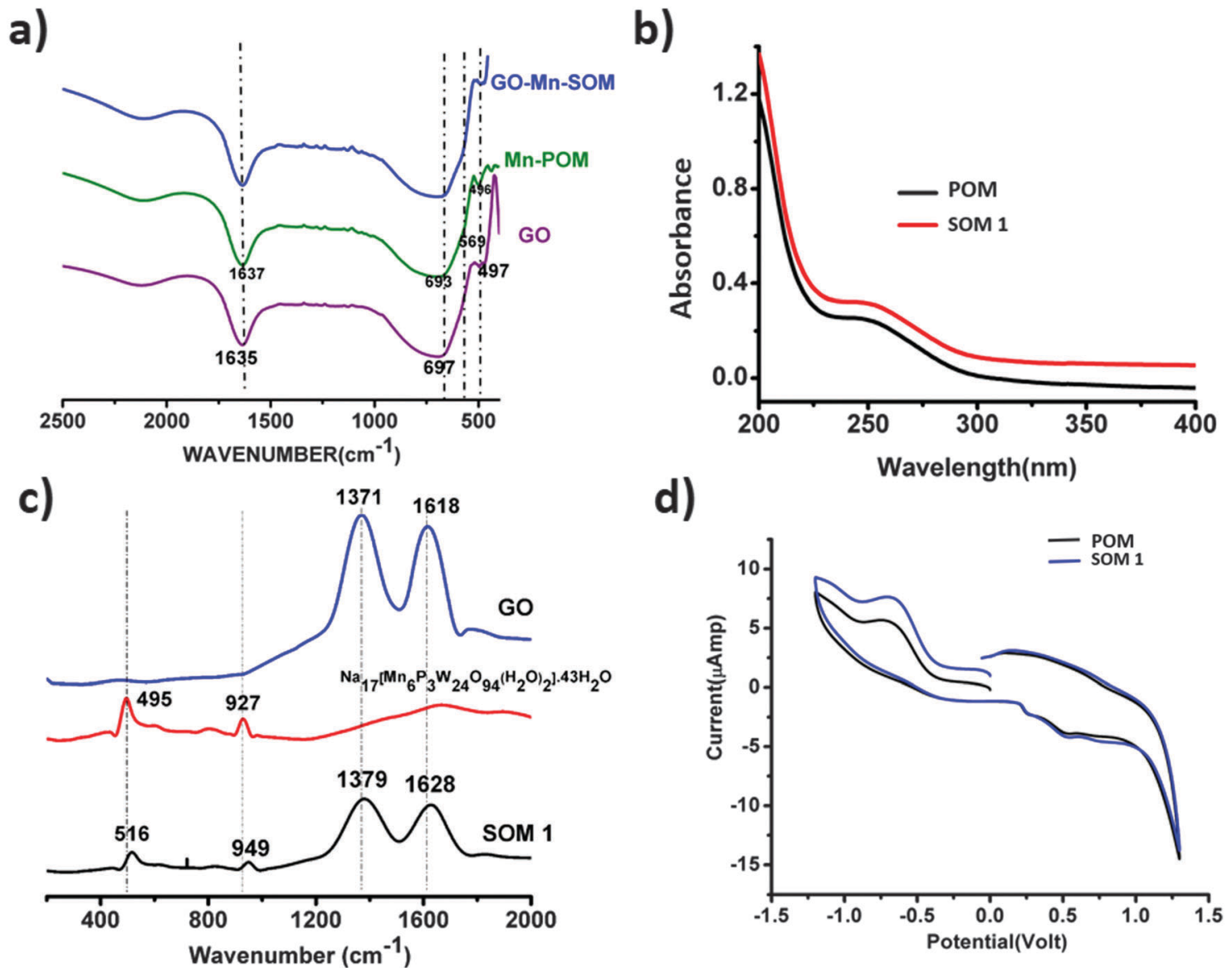

Fig. 4 (a) HATR-IR spectroscopy of the POM constituent, GO, and SOM 1. (b) UV-VIS spectroscopy of the POM constituent of SOM 1 and SOM 1. (c) Raman spectra of the POM unit $\mathrm{Na}_{17}\left[\mathrm{Mn}_{6} \mathrm{P}_{3} \mathrm{~W}_{24} \mathrm{O}_{94}\left(\mathrm{H}_{2} \mathrm{O}\right)_{2}\right] \cdot 43 \mathrm{H}_{2} \mathrm{O}$, graphene oxide and SOM 1. (d) Cyclic voltammogram of SOM 1 and the POM constituent of SOM 1

performed UV-VIS spectroscopy to check changes in the energy gap of the POM constituent after composite formation.

\section{UV-VIS spectroscopy of the POM constituent and SOM 1}

We performed UV-VIS spectroscopy of SOM 1 and the POM constituent in water. For both POM and SOM 1 we got absorbance maxima at $250 \mathrm{~nm}$ (Fig. 4b). Thus it may be concluded that the band gap of the POM constituent does not change in the SOM 1 composite, which further proves the stability of the POM constituent in SOM 1 because if it was dissociated to other cluster units then there should have been a clear difference in the UV-VIS spectrum.

\section{Raman spectroscopy and the nature of SOM 1}

We now want to show the effective formation of SOM. Raman spectra (Fig. 4c) of $\mathrm{Na}_{17}\left[\mathrm{Mn}_{6} \mathrm{P}_{3} \mathrm{~W}_{24} \mathrm{O}_{94}\left(\mathrm{H}_{2} \mathrm{O}\right)_{2}\right] \cdot 43 \mathrm{H}_{2} \mathrm{O}$, graphene oxide and the SOM 1 composite were taken; for SOM 1 we observed 4 peaks at 516, 949, 1379, and $1628 \mathrm{~cm}^{-1}$ respectively. We assign these peaks as follows: $516\left(\nu_{\text {as,Mn-O }}\right), 949\left(\nu_{\mathrm{W}=\mathrm{O}}\right)$ and the other two peaks at 1379 and $1628 \mathrm{~cm}^{-1}$ for disorder and graphitic nature of graphene oxide respectively. These peaks are blue shifted compared to that of the spectrum of graphene oxide and $\mathrm{Na}_{17}\left[\mathrm{Mn}_{6} \mathrm{P}_{3} \mathrm{~W}_{24} \mathrm{O}_{94}\left(\mathrm{H}_{2} \mathrm{O}\right)_{2}\right] \cdot 43 \mathrm{H}_{2} \mathrm{O}$ alone.
The Raman spectrum of $\mathrm{Na}_{17}\left[\mathrm{Mn}_{6} \mathrm{P}_{3} \mathrm{~W}_{24} \mathrm{O}_{94}\left(\mathrm{H}_{2} \mathrm{O}\right)_{2}\right] \cdot 43 \mathrm{H}_{2} \mathrm{O}$ shows peaks at 495 and $927 \mathrm{~cm}^{-1}$ which can be attributed to the following modes: $\left(\nu_{\mathrm{as}, \mathrm{Mn}-\mathrm{O}}\right),\left(\nu_{\mathrm{W}=\mathrm{O}}\right)$. The characteristic peaks at 1371 and $1618 \mathrm{~cm}^{-1}$ are on the other hand due to disorder and graphitic nature of graphene oxide respectively. This shift in the spectrum might indicate that there may be the possible presence of interaction between POM and the graphene oxide layer in SOM 1. In our system electrons are probably transferred from $\mathrm{Na}_{17}\left[\mathrm{Mn}_{6} \mathrm{P}_{3} \mathrm{~W}_{24} \mathrm{O}_{94}\left(\mathrm{H}_{2} \mathrm{O}\right)_{2}\right] \cdot 43 \mathrm{H}_{2} \mathrm{O}$ to graphene oxide. $^{62,63}$ This was further explained by $\mathrm{CV}$. We conclude from this shift that in SOM 1, graphene oxide may act as an electron acceptor and $\mathrm{Na}_{17}\left[\mathrm{Mn}_{6} \mathrm{P}_{3} \mathrm{~W}_{24} \mathrm{O}_{94}\left(\mathrm{H}_{2} \mathrm{O}\right)_{2}\right] \cdot 43 \mathrm{H}_{2} \mathrm{O}$ may act as an electron donor. The Raman spectrum also reveals that SOM 1 is not a physical mixture of the constituents graphene oxide and POM but an assembly of the two at the molecular level.

\section{Cyclic voltammogram of the catalyst}

To further monitor the stability of the POM constituent in SOM 1 we performed CV of SOM 1 and compared it with the CV of the POM constituent of SOM 1 (Fig. 4d) and it is clearly observed that both are identical, which indicates that the redox behavior of the POM constituent in SOM 1 remains unaltered and we can also conclude that the POM constituent is stable 

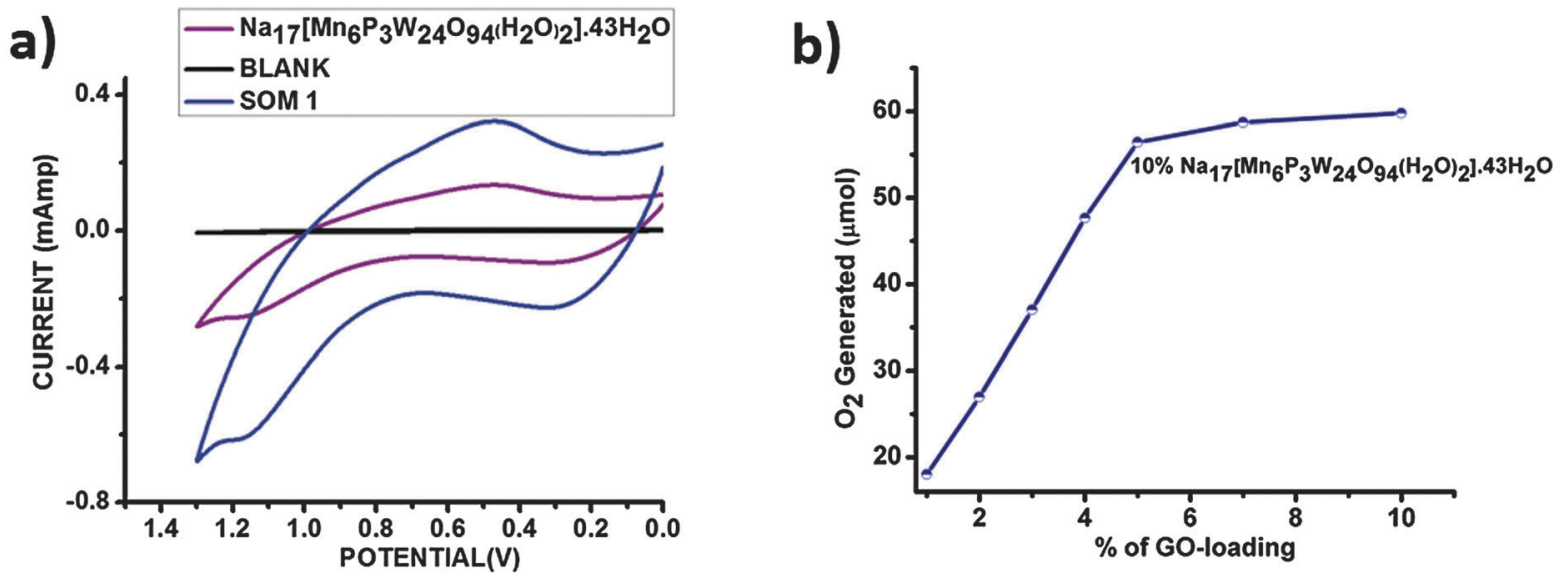

c)

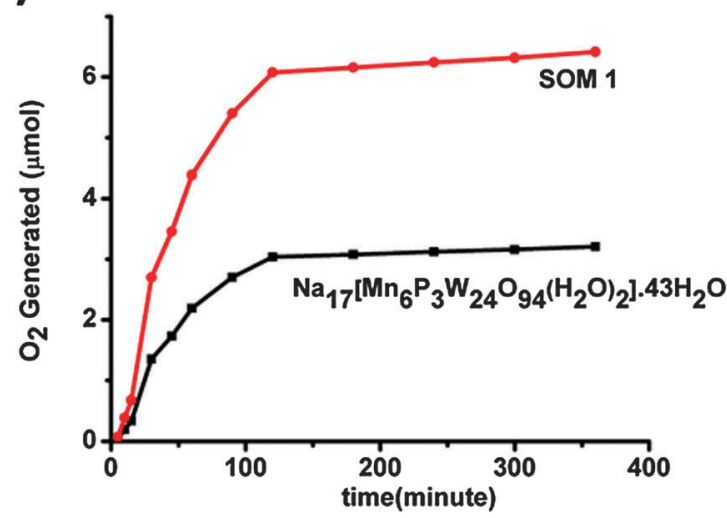

d)

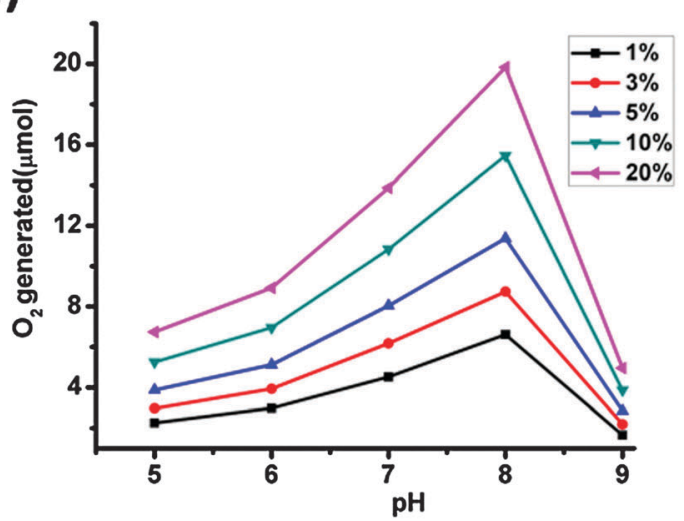

Fig. 5 (a) Cyclic voltammogram of the water oxidation study by the POM Na ${ }_{17}\left[\mathrm{Mn}_{6} \mathrm{P}_{3} \mathrm{~W}_{24} \mathrm{O}_{94}\left(\mathrm{H}_{2} \mathrm{O}\right)_{2}\right] \cdot 43 \mathrm{H}_{2} \mathrm{O}$ and SOM 1. (b) Extent of oxygen liberated with variation in graphene oxide-loading with $\mathrm{Na}_{17}\left[\mathrm{Mn}_{6} \mathrm{P}_{3} \mathrm{~W}_{24} \mathrm{O}_{94}\left(\mathrm{H}_{2} \mathrm{O}\right)_{2}\right] \cdot 43 \mathrm{H}_{2} \mathrm{O}$ concentration kept constant. (c) Comparative oxygen evolution by the $\mathrm{POM} \mathrm{Na}{ }_{17}\left[\mathrm{Mn}_{6} \mathrm{P}_{3} \mathrm{~W}_{24} \mathrm{O}_{94}\left(\mathrm{H}_{2} \mathrm{O}\right)_{2}\right] \cdot 43 \mathrm{H}_{2} \mathrm{O}$ only and SOM 1. (d) Variation of oxygen yield with $\mathrm{pH}$.

after composite formation. Also we observed that the peak current increased for SOM 1 which further indicates facile electron transport from the POM constituent to GO surface.

\section{Photochemical water splitting}

Photochemical water splitting experiments were performed under a UV lamp $\left(\lambda_{\max }=373 \mathrm{~nm}\right)$ with the composite catalyst system. The composites were prepared as mentioned in the previous section. The oxygen evolution was monitored using a YSI optical sensor based dissolved oxygen meter and also by cyclic voltammetry. The maximum oxygen yield obtained was $19.2 \mu \mathrm{mol}$ for $20 \%$ SOM 1 loading at pH 8 in phosphate buffer. The graphene oxide acts as an electron acceptor and traps the electrons released in the water oxidation reaction and facilitates electron transport as well.

\section{Confirmation of water oxidation and the effect of graphene oxide}

In our present work SOM 1 absorbed light and was elevated to the excited state. This excited SOM 1 generated hole and electron pairs, and the holes oxidized water to oxygen in the presence of light. After photoillumination quantitative determination of evolved oxygen was performed by measuring the evolved oxygen (Fig. 5c) using a YSI optical sensor based dissolved oxygen meter. For further confirmation of evolution of oxygen cyclic voltammetry (Fig. 5a) was performed using samples after photoirradiation, where a sudden rise of current was observed near $+1.2 \mathrm{~V}$ with respect to the $\mathrm{Ag} / \mathrm{AgCl}$ reference electrode indicative of oxygen evolution from water. It implies oxidation of water.

We observe that the extent of oxygen evolution is almost doubled in the case of the SOM 1 composite catalyst as compared to water oxidation by $\mathrm{Na}_{17}\left[\mathrm{Mn}_{6} \mathrm{P}_{3} \mathrm{~W}_{24} \mathrm{O}_{94}\left(\mathrm{H}_{2} \mathrm{O}\right)_{2}\right] \cdot 43 \mathrm{H}_{2} \mathrm{O}$ alone. Using POM alone the maximum amount of oxygen liberated is almost $3.2 \mu \mathrm{mol}$ for $0.071 \mu \mathrm{mol}$ loading of the catalyst, with a TON of around 46, whereas in the case of the SOM 1 composite catalyst system the amount of $\mathrm{O}_{2}$ evolved is almost $6.5 \mu \mathrm{mol}$ for $0.071 \mu \mathrm{mol}$ loading of the catalyst, with a TON of 92, which is roughly double than that of the POM alone. We thus investigate the role of graphene oxide in water oxidation.

In the next set of experiments, $\mathrm{Na}_{17}\left[\mathrm{Mn}_{6} \mathrm{P}_{3} \mathrm{~W}_{24} \mathrm{O}_{94}\left(\mathrm{H}_{2} \mathrm{O}\right)_{2}\right]$. $43 \mathrm{H}_{2} \mathrm{O}$ loading was kept constant $(10 \mathrm{mg} / 10 \mathrm{ml}$ in all the catalyst dispersions) and the graphene oxide concentration was increased (Fig. 5b). Here we observe a similar type of sigmoidal curves and the maximum $\mathrm{O}_{2}$ generation is almost 
$58 \mu \mathrm{mol}$ for $10 \%$ SOM 1 loading. The comparative studies clearly show that the increase of graphene oxide loading has a prominent effect on water oxidation. We observed two different aspects: (i) up to a certain loading of graphene oxide ( $5 \mathrm{mg}$ ) $\mathrm{O}_{2}$ evolution increases to a maximum of $58 \mu \mathrm{mol}$ and (ii) thereafter the increase of graphene oxide loading has no further effect on $\mathrm{O}_{2}$ evolution. We explain this as follows. With the increase in graphene oxide loading the extent of electron relay facilitated by graphene oxide increases, thereby increasing the effective $\mathrm{O}_{2}$ evolution. However beyond a certain threshold of graphene oxide loading the active POM concentration in SOM 1 gets diluted. Hence the evolution of $\mathrm{O}_{2}$ does not increase anymore.

Needless to say, graphene oxide invariably enhances the water oxidation activity. In SOM 1 we also infer that graphene oxide most likely (1) provides an enhanced active catalytic surface area and (2) facilitates electron transport and thereby enhances water oxidation effectively. Also one of the prominent reasons for the enhancement of water oxidation by using the GO matrix may be due to the increase in the effective surface area of the catalyst. In the case of SOM 1, the hydrodynamic radius is around $300 \mathrm{~nm}$ (from dynamic light scattering experiments) as compared to single SOM having a hydrodynamic radius of $130 \mathrm{~nm}$. We have calculated the surface area by assuming the catalyst materials to form nanospheres in dispersion and for a spherical surface we calculated the area by the following equation: surface area $=4 \pi R_{\mathrm{h}}{ }^{2}$. Now we address the problem of how water oxidation is affected with variation in $\mathrm{pH}$ and loading of SOM 1 dispersion in the next section.

\section{pH dependent study}

pH dependent water oxidation study reveals some interesting results (Fig. 5d). We observe that with the increase in $\mathrm{pH}$ the amount of evolved oxygen increases gradually. At $\mathrm{pH} 8$ we observe the maximum yield. On further increasing the $\mathrm{pH}$, oxygen evolution decreases abruptly and this may be attributed to the degradation of clusters at higher $\mathrm{pH}$. This observation may be explained by the shift of equilibrium involved with oxygen evolution to the right with the increase in $\mathrm{pH}$.

$$
\mathrm{H}_{2} \mathrm{O} \rightarrow \mathrm{O}_{2}+4 \mathrm{H}^{+}+4 \mathrm{e}^{-}
$$

\section{Catalyst loading variation studies}

In this set of experiments, the graphene oxide concentration is kept constant ( $1 \mathrm{mg} / 10 \mathrm{ml}$ in all the catalyst dispersions) and the SOM 1 loading is increased to observe the change in water oxidation. It is observed that with increasing POM loading oxygen evolution increases for a given $\mathrm{pH}$. The nature of the oxygen evolution curve with catalyst loading reveals that initially with increasing catalyst loading oxygen evolution increases rapidly, but after exceeding a certain loading of POM on SOM 1 catalyst (Fig. 6), the rate of enhancement of oxygen evolution in the reaction decreases to some extent. This may be due to the stability factor of the dispersion. More precisely oxygen evolution decreases when phase separation is observed and when we cross the dispersion stability window.

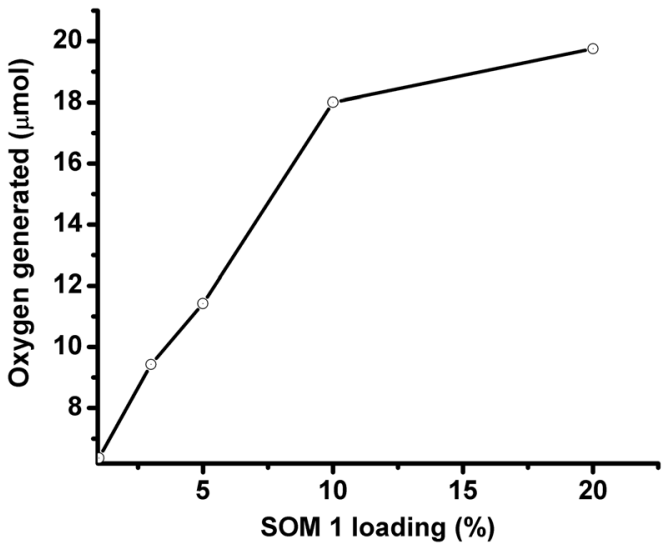

Fig. 6 Variation of SOM 1 loading at $\mathrm{pH} 7$.

This decrease in oxygen evolution is also due to the decrease in the active surface area of the catalyst.

\section{Time depended studies of oxygen evolution reaction}

Time dependent water oxidation experiments show general sigmoidal kinetic patterns typical of heterogeneous catalysis reactions, where up to a certain limit of time oxygen evolution increases and reaches a plateau (Fig. 7a). There is an induction

a)
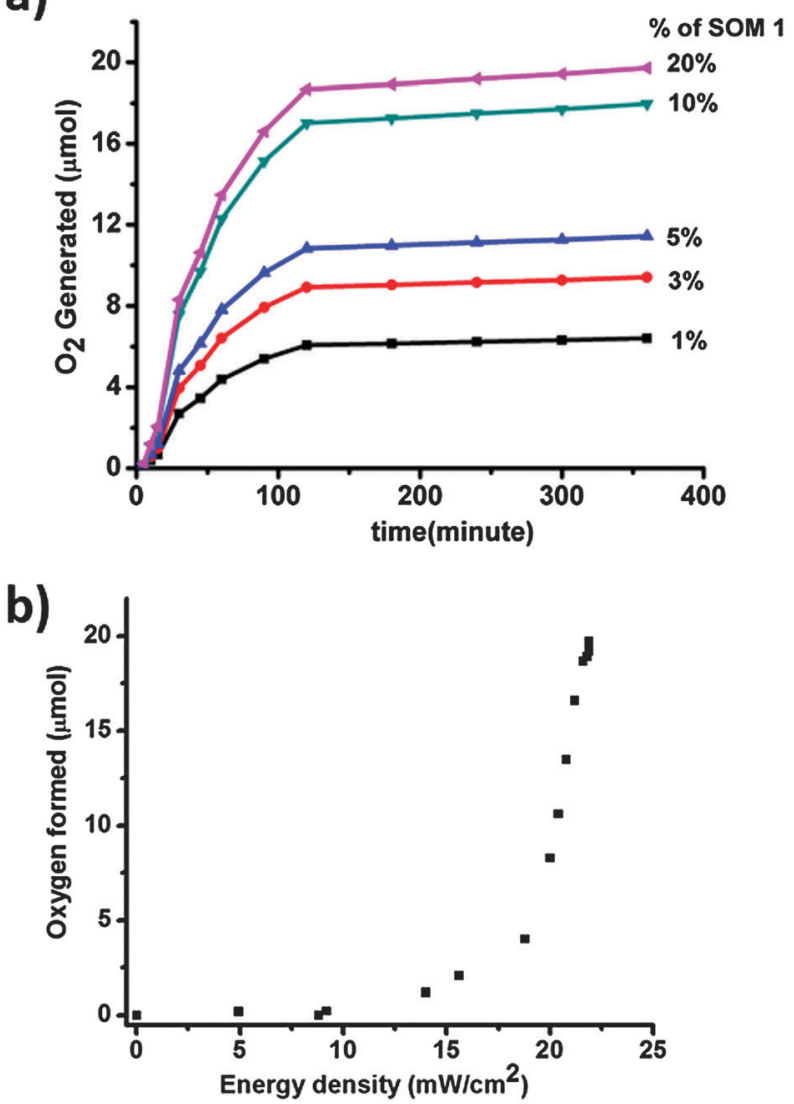

Fig. 7 (a) Concentration and time dependent water oxidation study. (b) Plot of energy density of the photoreactor with oxygen formed. 
a)
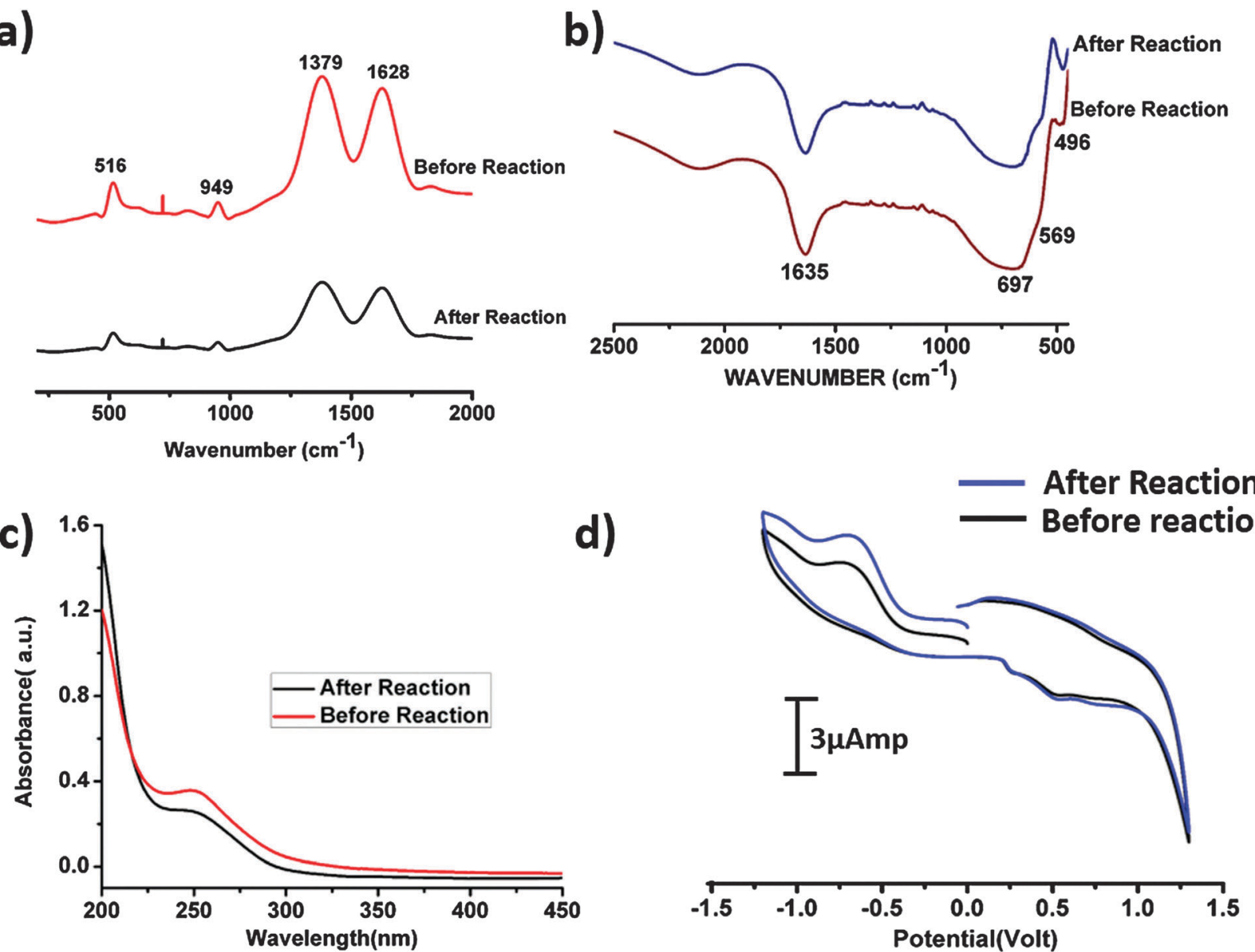

Fig. 8 (a) Raman spectrum of the SOM 1 catalyst before and after the reaction. (b) HATR-IR spectrum of the SOM 1 catalyst before and after the reaction. (c) UV-VIS spectrum of the SOM 1 catalyst before and after the reaction. (d) Cyclic voltammogram of the catalyst before and after the reaction.

period of reaction which may be due to light absorption limitation. For excitation of SOM 1 it needs to cross a minimum energy barrier, which is attained after some time and therefore initially there is no reaction. When SOM 1 possesses minimum energy for excitation water oxidation starts (Fig. 7b). As water is taken in excess in the reaction, the reaction rate only depends on the intensity of light and not on the amount of water present in the reaction medium. At early times of the reaction, i.e., at low light intensity (up to $9.32 \mathrm{~mW} \mathrm{~cm}^{-2}$ ) there is no $\mathrm{O}_{2}$ evolution. However, beyond a threshold light intensity $\left(9.32 \mathrm{~mW} \mathrm{~cm}^{-2}\right) \mathrm{O}_{2}$ evolution begins. The induction period (before threshold light intensity) probably simply reflects the time for $\mathrm{O}_{2}$ product equilibration before the analysis of evolved $\mathrm{O}_{2}$. It increases in a sigmoidal fashion suggesting co-operative photo-activation of the SOM sites for water oxidation. However with the increase in energy density oxygen evolution reaches saturation. Hence in other words it might be said that water oxidation reaction requires a threshold energy density to begin with, then increases in a sigmoidal fashion implying co-operative photo-activation of the SOM sites, finally reaching saturation with energy density. Thus it implies that the water oxidation reaction is topped off after a certain time. The maximum TOF of the reaction is $0.75 \mathrm{~min}^{-1}$ which is comparatively less than that of the recently developed photochemical water oxidation using cobalt based POM. This difference in TOF may be due to the involvement of different redox couples in the reaction. Here we observe that the maximum amount of $\mathrm{O}_{2}$ generated is almost $19 \mu \mathrm{mol}$ for $20 \%$ of SOM 1 loading. Now we ask whether SOM 1 is stable in the course of the reaction. To determine its stability we measured the Raman spectrum of SOM 1 before and after the completion of the reaction. A detailed account of this study is provided in the next section.

\section{Stability of the composite SOM catalyst}

Raman spectroscopic investigations were performed on the SOM 1 composite catalyst before and after the reaction. The spectra were observed to be identical (Fig. 8a). We also performed the HATR-IR (Fig. 8b) and UV-VIS (Fig. 8c) spectroscopy of the SOM 1 catalyst after the reaction. We also performed cyclic voltammetry (Fig. 8d) with the post reaction dispersion and in all the cases we observed identical spectra compared with the spectra obtained with the dispersion SOM 1 before the reaction. So we can possibly comprehend that the composite catalyst system remains intact during the water splitting reaction. Thus the reported catalyst system is stable under the water oxidation conditions that are used in this study. The POM 


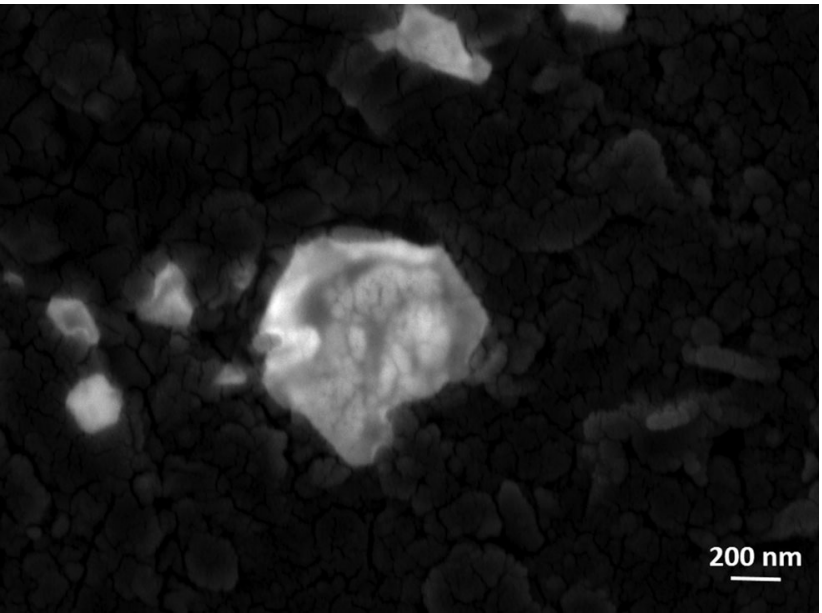

Fig. 9 SEM image of the post reaction SOM 1.

constituent does not dissociate to form $\mathrm{MnO}_{2}$ or some other fragment. Therefore during photochemical water oxidation reaction it is reasonable to believe that no $\mathrm{MnO}_{2}$ is generated under reaction conditions which can possibly oxidize water. Only the POM constituent is clearly responsible for the water oxidation reaction. More experiments and analyses are needed to pin-point the active species, excited species lifetime and other deeper mechanistic details which will be performed by us in the future. We also took SEM images (Fig. 9) of the post reaction composite catalyst and observed almost a similar kind of morphology as in the images taken before the commencement of the reaction.

\section{Catalytic recyclability of SOM 1}

As the catalyst is stable after the reaction, we can effectively reuse this catalyst for further catalytic cycles. For this purpose we checked the recyclability up to 10 catalytic cycles and we observed that each time an equal amount oxygen is evolved in the catalytic cycle (Fig. 10). Therefore the catalyst is completely reusable.

\section{Mechanism of evolution of $\mathrm{O}_{2}$ from water}

Photochemical water oxidation with polyoxometalates generally takes place in the presence of an additional photosensitizer and a sacrificial electron acceptor. In our present work, the photocatalytic

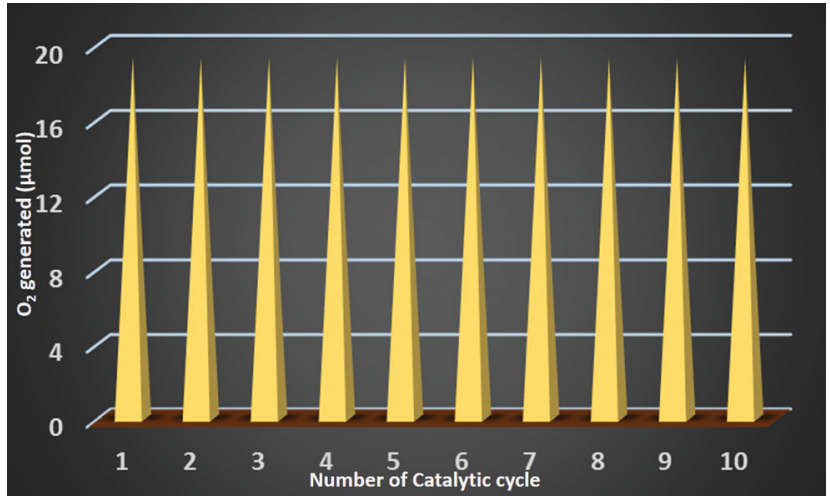

Fig. 10 Catalytic recyclability of the composite catalyst SOM 1.

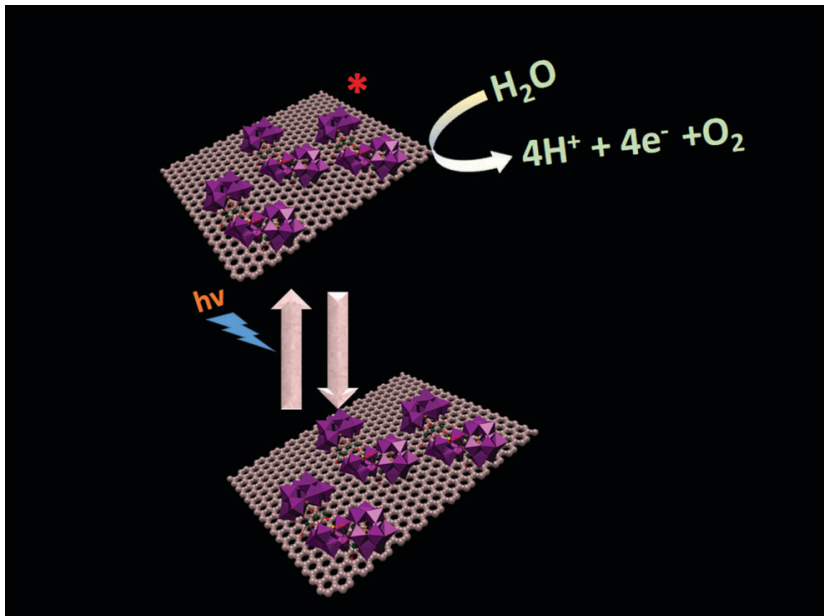

Fig. 11 Pathway of photochemical water oxidation.

heterogeneous reaction possibly follows a completely different pathway. Here we need not add any photosensitizer and sacrificial electron acceptor. SOM 1 itself may be absorbing light and going to the excited state which oxidizes water to oxygen (Fig. 11), but elucidation of the actual photophysical mechanism will require additional studies. To further prove that the excited species oxidized water we added catechol in the reaction and observed that water oxidation ceased under these conditions. This may be due to the fact that catechol oxidation is more favorable compared to water oxidation and therefore water oxidation does not take place in the presence of catechol. The graphene oxide sheets are expected to act as electron acceptor platforms for the electrons generated in the water oxidation process ${ }^{64,65}$ and also enhance the surface area of the POM constituent of SOM 1.

\section{Conclusion}

To summarize, we have demonstrated the water oxidation by $\mathrm{Mn}$ polyoxometalate (POM) based soft-oxometalate (SOM 1) dispersion and the efficiency is almost doubled by immobilizing Mn-POM on an electroactive graphene oxide matrix. The catalyst system acts as a water oxidizing agent to generate oxygen under photochemical conditions. The graphene oxide layers possibly act as electron acceptors and surface area enhancers and facilitate water oxidation by SOM 1. Thereafter we describe the effect of catalyst loading and $\mathrm{pH}$ on photocatalytic water-splitting. From the kinetics of the reaction we show the operation of heterogeneous mode of catalysis. After demonstrating the stability of the catalyst in the course of the water splitting reaction we have proposed the plausible pathway of the catalyst action. Further work is in progress in our laboratory in order to design more SOM based water splitting catalysts.

\section{Experimental procedure}

\section{Materials and reagents}

All the materials were purchased from commercially available sources and used without further purification. All the glass 
apparatus were first boiled in an acid bath, then in water and finally rinsed with acetone. All the glass apparatus were properly dried in a hot air oven overnight. Doubly distilled deionized water was used to carry out all the experiments.

\section{Synthesis of graphene oxide}

Graphene oxide was synthesized by the improved Hummers' method. ${ }^{66-68}$ Hummers' method ${ }^{69}\left(\mathrm{KMnO}_{4}, \mathrm{NaNO}_{3}, \mathrm{H}_{2} \mathrm{SO}_{4}\right)$ is the most common method used for preparing graphene oxide. A recent methodology study has modified the process to some extent and improved the efficiency of the oxidation process and this modified Hummers' method ${ }^{68}$ was employed here to synthesize graphene oxide for our experiments.

Concentrated $\mathrm{H}_{2} \mathrm{SO}_{4}(69 \mathrm{ml})$ was added to a mixture of graphite flakes (3.0 g, 1 wt equiv.) and $\mathrm{NaNO}_{3}(1.5 \mathrm{~g}, 0.5 \mathrm{wt}$ equiv.), and the mixture was cooled using an ice bath to $0{ }^{\circ} \mathrm{C}$. $\mathrm{KMnO}_{4}$ (9.0 g, 3 wt equiv.) was added slowly to keep the reaction temperature below $20{ }^{\circ} \mathrm{C}$ as $\mathrm{KMnO}_{4}$ addition is exothermic. The reaction was warmed to $35{ }^{\circ} \mathrm{C}$ and stirred for 7 h. Additional $\mathrm{KMnO}_{4}$ (9.0 g, 3 wt equiv.) was added in one portion, and the reaction was stirred for $12 \mathrm{~h}$ at $35{ }^{\circ} \mathrm{C}$. The reaction mixture was cooled to room temperature and poured into ice with $30 \% \mathrm{H}_{2} \mathrm{O}_{2}(3 \mathrm{ml})$. The mixture was then purified following the usual protocol of sifting, filtering, centrifugation, decanting with multiple washes followed by a final vacuum drying to give $4.0 \mathrm{~g}$ of solid product.

\section{Synthesis of SOM 1}

$1 \mathrm{mg}$ of graphene oxide was added into $10 \mathrm{ml}$ of water and $2 \mathrm{ml}$ of ethylene glycol was added to it for better separation of the graphene oxide sheets. Then it was sonicated for 3 hours at room temperature to prepare graphene oxide dispersion. After that, $10 \mathrm{mg}$ of $\mathrm{Na}_{17}\left[\mathrm{Mn}_{6} \mathrm{P}_{3} \mathrm{~W}_{24} \mathrm{O}_{94}\left(\mathrm{H}_{2} \mathrm{O}\right)_{2}\right] \cdot 43 \mathrm{H}_{2} \mathrm{O}$ was added and the dispersion was sonicated for 3 more hours. The stability of the dispersion was checked and it was found to be stable.

\section{Photocatalytic water splitting}

Photocatalytic water splitting reactions were performed as follows. In the composite dispersion for water oxidation experiment buffer solution of $\mathrm{pH} 7$ was added. The reaction mixture was then sealed and $\mathrm{N}_{2}$ gas was purged for 3 hours to get rid of the trace amount of oxygen in it. Then the reaction mixture was kept in a photoreactor under UV-light (energy density of the photoreactor is $-19.5 \mathrm{~mW} \mathrm{~cm} \mathrm{~cm}^{-2}$ with $\lambda_{\max }=373 \mathrm{~nm}$ ) for 2 hours. After irradiation we measured the amount of evolved oxygen in the reaction by using YSI optical sensor based dissolved oxygen meter standardized by using degassed double distilled water. Evolution of oxygen in the reaction was further investigated by performing cyclic voltammetry using the irradiated samples. In cyclic voltammetry we observed a sharp rise of the current-voltage curve near $+1.2 \mathrm{~V}$, which is typically indicative of $\mathrm{O}_{2}$ generation by water splitting.

\section{pH dependent water splitting}

This experiment was performed by following the previous procedure using different buffer solutions in the $\mathrm{pH}$ range of
5 to 9 . Measurement of oxygen evolution was carried out by a similar method mentioned earlier.

\section{Characterization techniques}

SEM-EDX microscopy. SEM measurements were done by drop-casting SOM 1 dispersion on a silicon wafer and drying under vacuum for 2 days. Then SEM imaging was performed and images were taken on a SUPRA 55 VP-41-32 instrument with the Smart SEM version 5.05 Zeiss software.

Cyclic voltammetry. A PAR model 273 potentiostat was used for $\mathrm{CV}$ experiments. A platinum wire auxiliary electrode, a glassy carbon working electrode with a surface area of $0.002826 \mathrm{~cm}^{2}$ and an aqueous $\mathrm{Ag} / \mathrm{Ag}^{+}$reference electrode which is filled with saturated $\mathrm{KCl}$ solution were used in a three electrode configuration. The scan rate was $0.5 \mathrm{~V} \mathrm{~s}^{-1}$. The $\mathrm{CV}$ spectrum was recorded in the range of 0 to $+1.3 \mathrm{~V}$. Blank refers to the amount of oxygen present in distilled water in our mentioned reaction conditions. The $\mathrm{pH}$ of the medium was 7. 0.1 M KCl solution was used as a supporting electrolyte in all the experiments. All measurements were done at $298 \mathrm{~K}$ in an inert atmosphere.

Dynamic light scattering measurements. The average size of the particle was obtained using the dynamic light scattering method in a Malvern Zetasizer instrument. A very dilute solution of SOM 1 was prepared by further dilution of the SOM 1 dispersion and taken in a fluorescence glass cuvette with a square aperture and the instrument was set to take 15 runs before measuring the average hydrodynamic radius of the SOM 1 composite.

Raman spectroscopy. A LABRAM HR800 Raman spectrometer was employed using the $633 \mathrm{~nm}$ line of a He-Ne ion laser $(\lambda=633 \mathrm{~nm})$ as the excitation source to analyze the sample.

\section{Acknowledgements}

SR gratefully acknowledges the grants from IISER-Kolkata, India, DST-fast track and BRNS-DAE grant.

\section{References}

1 D. G. Nocera, Acc. Chem. Res., 2012, 45, 767-776.

2 M. Jacobson, W. Colella and D. Golden, Science, 2005, 308, 1901-1905.

3 L. Hammarström and S. Hammes-Schiffer, Acc. Chem. Res., 2009, 42, 1859-1860.

4 L. S. Dennis and G. H. Hetterscheid, Eur. J. Inorg. Chem., 2014, 568-790.

5 J. J. Concepcion, J. W. Jurss, J. L. Templeton and T. J. Meyer, Proc. Natl. Acad. Sci. U. S. A., 2008, 105, 17632-17635.

6 Q. Yin, J. M. Tan, C. Besson, Y. V. Geletii, D. G. Musaev, A. E. Kuznetsov, Z. Luo, K. I. Hardcastle and C. L. Hill, Science, 2010, 328, 342-345.

7 Y. Zhao, J. R. Swierk, J. D. Megiatto, B. Sherman, W. J. Youngblood, D. Qin, D. M. Lentz, A. L. Moore, T. A. Moore and D. Gust, Proc. Natl. Acad. Sci. U. S. A., 2012, 109, 15612-15616. 
8 G. Zhu, E. N. Glass, C. Zhao, H. Lv, J. W. Vickers, Y. V. Geletii, D. G. Musaev, J. Song and C. L. Hill, Dalton Trans., 2012, 41, 13043-13049.

9 L. Duan, F. Bozoglian, S. Mandal, B. Stewart, T. Privalov, A. Llobet and L. Sun, Nat. Chem., 2012, 4, 418-423.

10 L. Francas, X. Sala, E. Escudero-Adán, J. Benet-Buchholz, L. Escriche and A. Llobet, Inorg. Chem., 2011, 50, 2771-2781.

11 I. López, M. Z. Ertem, S. Maji, J. Benet-Buchholz, A. Keidel, U. Kuhlmann, P. Hildebrandt, C. J. Cramer, V. S. Batista and A. Llobet, Angew. Chem., 2014, 126, 209-213.

12 J. K. Hurst, Coord. Chem. Rev., 2005, 249, 313-328.

13 S. Roeser, P. Farràs, F. Bozoglian, M. Martínez-Belmonte, J. Benet-Buchholz and A. Llobet, ChemSusChem, 2011, 4, 197-207.

14 J. F. Hull, D. Balcells, J. D. Blakemore, C. D. Incarvito, O. Eisenstein, G. W. Brudvig and R. H. Crabtree, J. Am. Chem. Soc., 2009, 131, 8730-8731.

15 N. S. McCool, D. M. Robinson, J. E. Sheats and G. C. Dismukes, J. Am. Chem. Soc., 2011, 133, 11446-11449.

16 R. Zong and R. P. Thummel, J. Am. Chem. Soc., 2005, 127, 12802-12803.

17 J. J. Concepcion, J. W. Jurss, M. K. Brennaman, P. G. Hoertz, A. O. T. Patrocinio, N. Y. Murakami Iha, J. L. Templeton and T. J. Meyer, Acc. Chem. Res., 2009, 42, 1954-1965.

18 N. D. McDaniel, F. J. Coughlin, L. L. Tinker and S. Bernhard, J. Am. Chem. Soc., 2008, 130, 210-217.

19 J. T. Muckerman, D. E. Polyansky, T. Wada, K. Tanaka and E. Fujita, Inorg. Chem., 2008, 47, 1787-1802.

20 M. W. Kanan and D. G. Nocera, Science, 2008, 321, 1072-1075.

21 D. M. Robinson, Y. B. Go, M. Greenblatt and G. C. Dismukes, J. Am. Chem. Soc., 2010, 132, 11467-11469.

22 A. Indra, P. W. Menezes, I. Zaharieva, E. Baktash, J. Pfrommer, M. Schwarze, H. Dau and M. Driess, Angew. Chem., Int. Ed., 2013, 52, 13206-13210.

23 S. M. Barnett, K. I. Goldberg and J. M. Mayer, Nat. Chem., 2012, 4, 498-502.

24 A. K. Vannucci, L. Alibabaei, M. D. Losego, J. J. Concepcion, B. Kalanyan, G. N. Parsons and T. J. Meyer, Proc. Natl. Acad. Sci. U. S. A., 2013, 110, 20918-20922.

25 F. Jiao and H. Frei, Angew. Chem., Int. Ed., 2009, 48, 1841-1844.

26 T. Zidki, L. Zhang, V. Shafirovich and S. V. Lymar, J. Am. Chem. Soc., 2012, 134, 14275-14278.

27 R. D. Smith, M. S. Prévot, R. D. Fagan, Z. Zhang, P. A. Sedach, M. K. J. Siu, S. Trudel and C. P. Berlinguette, Science, 2013, 340, 60-63.

28 T. W. Kim and K.-S. Choi, Science, 2014, 343, 990-994.

29 M. Quintana, A. M. López, S. Rapino, F. M. Toma, M. Iurlo, M. Carraro, A. Sartorel, C. Maccato, X. Ke and C. Bittencourt, ACS Nano, 2012, 7, 811-817.

30 A. Sartorel, M. Carraro, G. Scorrano, R. D. Zorzi, S. Geremia, N. D. McDaniel, S. Bernhard and M. Bonchio, J. Am. Chem. Soc., 2008, 130, 5006-5007.

31 Y. V. Geletii, Z. Huang, Y. Hou, D. G. Musaev, T. Lian and C. L. Hill, J. Am. Chem. Soc., 2009, 131, 7522-7523.
32 C. Besson, Z. Huang, Y. V. Geletii, S. Lense, K. I. Hardcastle, D. G. Musaev, T. Lian, A. Proust and C. L. Hill, Chem. Commun., 2010, 46, 2784-2786.

33 F. M. Toma, A. Sartorel, M. Iurlo, M. Carraro, P. Parisse, C. Maccato, S. Rapino, B. R. Gonzalez, H. Amenitsch and T. Da Ros, Nat. Chem., 2010, 2, 826-831.

34 M. Murakami, D. Hong, T. Suenobu, S. Yamaguchi, T. Ogura and S. Fukuzumi, J. Am. Chem. Soc., 2011, 133, 11605-11613.

35 G. Zhu, Y. V. Geletii, P. Kögerler, H. Schilder, J. Song, S. Lense, C. Zhao, K. I. Hardcastle, D. G. Musaev and C. L. Hill, Dalton Trans., 2012, 41, 2084-2090.

36 S. Tanaka, M. Annaka and K. Sakai, Chem. Commun., 2012, 48, 1653-1655.

37 H. Lv, Y. V. Geletii, C. Zhao, J. W. Vickers, G. Zhu, Z. Luo, J. Song, T. Lian, D. G. Musaev and C. L. Hill, Chem. Soc. Rev., 2012, 41, 7572-7589.

38 J. Soriano-López, S. Goberna-Ferrón, L. Vigara, J. J. Carbó, J. M. Poblet and J. R. N. Galán-Mascarós, Inorg. Chem., 2013, 52, 4753-4755.

39 S. Goberna-Ferrón, L. Vigara, J. n. Soriano-López and J. R. N. Galán-Mascarós, Inorg. Chem., 2012, 51, 11707-11715.

40 J. W. Vickers, H. Lv, J. M. Sumliner, G. Zhu, Z. Luo, D. G. Musaev, Y. V. Geletii and C. L. Hill, J. Am. Chem. Soc., 2013, 135, 14110-14118.

41 R. Al-Oweini, A. Sartorel, B. S. Bassil, M. Natali, S. Berardi, F. Scandola, U. Kortz and M. Bonchio, Angew. Chem., Int. Ed., 2014, 53, 11182-11185.

42 J. M. Sumliner, H. Lv, J. Fielden, Y. V. Geletii and C. L. Hill, Eur. J. Inorg. Chem., 2014, 635-644.

43 S. Chatterjee, K. Sengupta, S. Dey and A. Dey, Inorg. Chem., 2013, 52, 14168-14177.

44 Y. Gorlin, B. Lassalle-Kaiser, J. D. Benck, S. Gul, S. M. Webb, V. K. Yachandra, J. Yano and T. F. Jaramillo, J. Am. Chem. Soc., 2013, 135, 8525-8534.

45 S. Dey, B. Mondal and A. Dey, Phys. Chem. Chem. Phys., 2014, 16, 12221-12227.

46 D. K. Zhong and D. R. Gamelin, J. Am. Chem. Soc., 2010, 132, 4202-4207.

47 S. Hoang, S. Guo, N. T. Hahn, A. J. Bard and C. B. Mullins, Nano Lett., 2011, 12, 26-32.

48 W. J. Jo, J. W. Jang, K. j. Kong, H. J. Kang, J. Y. Kim, H. Jun, K. Parmar and J. S. Lee, Angew. Chem., Int. Ed., 2012, 51, 3147-3151.

49 Y. H. Ng, A. Iwase, A. Kudo and R. Amal, J. Phys. Chem. Lett., 2010, 1, 2607-2612.

50 M. Kato, T. Cardona, A. W. Rutherford and E. Reisner, J. Am. Chem. Soc., 2012, 134, 8332-8335.

51 G. Wang, Y. Ling and Y. Li, Nanoscale, 2012, 4, 6682-6691. 52 Y. Hou, F. Zuo, A. Dagg and P. Feng, Angew. Chem., 2013, 125, 1286-1290.

53 Z. Huang, Z. Luo, Y. V. Geletii, J. W. Vickers, Q. Yin, D. Wu, Y. Hou, Y. Ding, J. Song and D. G. Musaev, J. Am. Chem. Soc., 2011, 133, 2068-2071.

54 W. J. Youngblood, S.-H. A. Lee, Y. Kobayashi, E. A. Hernandez-Pagan, P. G. Hoertz, T. A. Moore, A. L. Moore, 
D. Gust and T. E. Mallouk, J. Am. Chem. Soc., 2009, 131, 926-92755.

55 J. M. Thomsen, D. L. Huang, R. H. Crabtree and G. W. Brudvig, Dalton Trans., 2015, 44, 12452-12472.

56 S. Roy, M. C. Mourad and M. T. Rijneveld-Ockers, Langmuir, 2007, 23, 399-401.

57 S.-X. Guo, Y. Liu, C.-Y. Lee, A. M. Bond, J. Zhang, Y. V. Geletii and C. L. Hill, Energy Environ. Sci., 2013, 6, 2654-2663. 58 S. Roy, CrystEngComm, 2014, 16, 4667-4676.

59 B. Roy, M. Arya, P. Thomas, J. K. Jürgschat, K. Venkata Rao, A. Banerjee, C. Malla Reddy and S. Roy, Langmuir, 2013, 29, 14733-14742.

60 S. Roy, Comments Inorg. Chem., 2011, 32, 113-126.

61 S. Roy, H. J. Meeldijk, A. V. Petukhov, M. Versluijs and F. Soulimani, Dalton Trans., 2008, 2861-2865.

62 P. D. Tran, S. K. Batabyal, S. S. Pramana, J. Barber, L. H. Wong and S. C. J. Loo, Nanoscale, 2012, 4, 3875-3878.
63 H. Li, S. Pang, X. Feng, K. Müllen and C. Bubeck, Chem. Commun., 2010, 46, 6243-6245.

64 A. Iwase, Y. H. Ng, Y. Ishiguro, A. Kudo and R. Amal, J. Am. Chem. Soc., 2011, 133, 11054-11057.

65 S.-S. Li, K.-H. Tu, C.-C. Lin, C.-W. Chen and M. Chhowalla, ACS Nano, 2010, 4, 3169-3174.

66 S. Stankovich, D. A. Dikin, R. D. Piner, K. A. Kohlhaas, A. Kleinhammes, Y. Jia, Y. Wu, S. T. Nguyen and R. S. Ruoff, Carbon, 2007, 45, 1558-1565.

67 D. A. Dikin, S. Stankovich, E. J. Zimney, R. D. Piner, G. H. Dommett, G. Evmenenko, S. T. Nguyen and R. S. Ruoff, Nature, 2007, 448, 457-460.

68 D. C. Marcano, D. V. Kosynkin, J. M. Berlin, A. Sinitskii, Z. Sun, A. Slesarev, L. B. Alemany, W. Lu and J. M. Tour, ACS Nano, 2010, 4, 4806-4814.

69 W. Hummers and R. Offeman, J. Am. Chem. Soc., 1958, 80, 1339. 